\title{
BMJ Open Impact of the New Cooperative Medical Scheme on the trend of catastrophic health expenditure in Chinese rural households: results from nationally representative surveys from 2003 to 2013
}

Biao Xie, ${ }^{1}$ Minghe Huo, ${ }^{2}$ Zhiqiang Wang, ${ }^{3}$ Yongjie Chen, ${ }^{1}$ Rong Fu, ${ }^{4}$ Meina Liu, ${ }^{1}$ Qun Meng ${ }^{2}$

To cite: Xie B, Huo M, Wang Z, et al. Impact of the New Cooperative Medical Scheme on the trend of catastrophic health expenditure in Chinese rural households: results from nationally representative surveys from 2003 to 2013. BMJ Open 2018;8:e019442. doi:10.1136/ bmjopen-2017-019442

- Prepublication history and additional material for this paper are available online. To view these files, please visit the journal online (http://dx.doi. org/10.1136/bmjopen-2017019442).

Received 1 September 2017 Revised 19 December 2017 Accepted 20 December 2017

Check for updates

${ }^{1}$ Department of Biostatistics, Public Health College, Harbin Medical University, Harbin, China ${ }^{2}$ Department of Health Management, Public Health College, Harbin Medical University, Harbin, China

${ }^{3}$ School of Medicine, Royal Brisbane and Women's Hospital, University of Queensland, Herston, Queensland, Australia ${ }^{4}$ Department of Epidemiology and Biostatistics, Public Health College, Fujian Medical University, Fuzhou, China

Correspondence to

Professor Meina Liu; liumeina369@163.com

\section{ABSTRACT}

Objective To evaluate the trend of catastrophic health expenses (CHE) for inpatient care in relation to the commencement of the New Cooperative Medical Scheme (NCMS) in rural China from 2003 to 2013, and the roles of NCMS in protecting affected households from CHE.

Methods We assessed the 10-year trend of the incidence and severity of CHE in rural households with hospitalised members using data from the Chinese National Health Services Survey. Generalised estimating equations were used to estimate the $\mathrm{OR}$ and $95 \% \mathrm{Cl}$ of the association between incidence rates of $\mathrm{CHE}\left(R_{C H E}\right)$ and NCMS reimbursement.

Results The incidence and severity of CHE after NCMS reimbursement both decreased and their changes increased rapidly from 2003 to 2013. After adjustment of the covariates, $R_{C H E}$ before reimbursement was significantly higher than that after reimbursement, and the $\mathrm{OR}(95 \% \mathrm{Cl})$ was 1.50 (1.24 to 1.81$), 1.79$ (1.69 to 1.90 ) and 2.94 (2.77 to 3.11) in 2003, 2008 and 2013, respectively.

Conclusion The incidence and severity of CHE both reduced after NCMS reimbursements in each year. Excluding some confounding factors, $R_{C H E}$ was significantly associated with NCMS reimbursement. NCMS partly protected the rural households with hospitalised members from CHE. However, the inequalities between different income groups still existed. $R_{C H E}$ in rural households with hospitalised members was still rather high in 2003, 2008 and 2013 even though they were covered by NCMS. This study will provide suggestions for further reforms in China and guidance for other lowincome/middle-income countries.

\section{INTRODUCTION}

The New Cooperative Medical Scheme (NCMS) was introduced to rural China in 2003. It was designed to provide financial protection for its enrollees. In terms of the enrolment size, NCMS is by far the largest health insurance plan in the world. ${ }^{1}$ Catastrophic health expense (CHE)
Strengths and limitations of this study

- Generalised estimating equations were used to estimate the $\mathrm{OR}$ and $95 \% \mathrm{Cl}$ of the association between the catastrophe's incidence and the New Cooperative Medical Scheme reimbursement

- We assessed the 10-year trend of the incidence and severity of catastrophic health expenses at the national level using data from the Chinese National Health Services Survey.

- Three indicators were used to capture the catastrophe's incidence and intensity.

- The sample size in 2003 was small with only 180 households.

is defined as an out-of-pocket health expenditure that is larger than $40 \%$ of the household's capacity to pay (CTP). ${ }^{2}$ CHE is an indicator reflecting the effectiveness of financial protection a health insurance could provide for its members. In 2008, $15.1 \%$ of the rural households and $35.0 \%$ of the rural households with hospitalised members faced CHE in China. ${ }^{3}{ }^{4}$ It was essential to evaluate the role of NCMS in preventing CHE among its members. There had been many studies measuring the impact of NCMS. However, most studies focused on a specific local area or the short-term effect of NCMS on CHE in China. ${ }^{3-10}$ NCMS focused on inpatient care reimbursement. Among studies on the impact of NCMS on CHE, those focusing on affected rural households with hospitalised members were valuable. However, few previous studies had focused on such affected rural households.

We assessed the 10-year trend of the incidence and severity of CHE in rural households with hospitalised members at the national level using data from the Chinese National 
Health Services Survey (NHSS). The trend of CHE for inpatient care in relation to the commencement of NCMS in rural China from 2003 to 2013 and the roles of NCMS in protecting affected households from CHE can provide evidence for NCMS in improving financial protection for Chinese residents. As an exploratory attempt to study the impact of NCMS on the CHE of rural households with hospitalised members, this study can provide some recommendations on the next phase of health reform for policy-makers.

\section{METHODS}

\section{Data source and study population}

Data used in this study were derived from the Chinese third NHSS in 2003, the fourth NHSS in 2008 and the fifth NHSS in 2013. As the largest state-wide health survey in China, the NHSS has been organised by the Chinese government every 5 years since 1993. All data in the NHSS were collected using a structured questionnaire, the validity and reliability of which had been demonstrated. ${ }^{11}{ }^{12}$ The NHSS was done with a robust multistage and stratified random cluster sampling method. ${ }^{13}$ A total of 94 counties were selected from 2859 counties in 31 provinces, autonomous regions and municipalities in China. In each county, five townships were selected within which two villages were selected. A total of 470 townships and 940 villages were included. In each village, 60 households were selected. ${ }^{14}$ A district survey manager checked the questionnaires at the end of each day to avoid missing information or logic errors. Of the sampled households, $5 \%$ was randomly selected to be revisited to examine survey quality (95\% was achieved).${ }^{13}$ According to a test conducted by the Health Statistical Center of the Ministry of Health of China, the survey data were representative of the structure of the overall national population compared with the 2007 National Sampling Survey of Population Change. ${ }^{13}$

This study focused on the incidence and severity of CHE of rural households with hospitalised members covered by NCMS. Households that did not join NCMS or did not use inpatient services were not covered. This yielded a final sample of 6975 households, which experienced inpatient care during the study period (180 in 2003, 2326 in 2008 and 4469 in 2013).

\section{The introduction of indicators}

Out-of-pocket health expenditure payment (OOP) refers to the expenditure made by each household member after they receive health services without compensations from a third party. The poverty line is the average food expenditure of households of which food share is in the 45th-55th percentile range. The detailed definition of poverty line used in the study is shown in the online supplementary materials. This poverty line multiplied by the equalised household size (actual household size: 0.56) is household subsistence spending. CTP is generally defined as a non-subsistence spending. However, when food expenditure is lower than subsistence spending in some households, the non-food expenditure is used as non-subsistence spending in this particular situation. ${ }^{14}$ The questions contained on the NHSS questionnaire employed to calculate the indicators below are shown in the online supplementary materials.

\section{Incidence rates of $\mathrm{CHE}$}

There were various definitions of CHE, and in this study we employed the method recommended by the WHO for calculating CHE. An OOP is considered financially catastrophic when it is larger than $40 \%$ of the household's CTP. ${ }^{1}$ Let $R_{\mathrm{CHE}}$ denote the incidence rates of CHE, which can be calculated as:

$$
R_{\mathrm{CHE}}=\frac{1}{N} \sum_{i=1}^{N} E_{i}
$$

where $N$ represents the sample size. $E_{i}=1$ when $\frac{O O P}{C T P} \geq 0.4 ; E_{i}=0$ when $\frac{O O P}{C T P}<0.4$.

Definitions and calculations of mean CHE gap $\left(G_{\mathrm{CHE}}\right)$ and mean positive CHE gap ( $\left.M P G_{\text {CHE }}\right)$

The $G_{\mathrm{CHE}}$ describes how much of a household's health expenditure is in excess of the threshold of $40 \%$ of its CTP, which is estimated to reveal the average level of CHE severity for all studied households. The $M P G_{\mathrm{CHE}}$ refers to the average of the sum of the total excesses from all the catastrophic households in the sample. ${ }^{1} G_{\mathrm{CHE}}$ and $M P G_{\mathrm{CHE}}$ can be calculated as:

$$
\begin{gathered}
G_{\mathrm{CHE}}=\frac{1}{N} \sum_{i=1}^{N} O_{i} \\
M P G_{\mathrm{CHE}}=\frac{\sum_{i=1}^{N} O_{i}}{\sum_{i=1}^{N} E_{i}}
\end{gathered}
$$

where $O_{i}=\frac{O O P}{C T P}-0.4$ when $\frac{O O P}{C T P}>0.4 ; O_{i}=0$ when $\frac{O O P}{C T P} \leq 0.4$.

\section{The introduction of GEE}

The generalised estimating equation (GEE) is based on the quasi-likelihood function and generalised linear model. It can be used to resolve repeated-measures issues. ${ }^{15-17}$ GEE has the following advantages:

1. More robust modelling: When connectivity function of GEE is correct, we can get stable parameter estimates even if the correlation matrix is chosen randomly.

2. Flexibility: The dependent variable of GEE can follow any kind of exponential distribution. Various covariance structures can also be chosen. ${ }^{15-17}$

In this study, the $R_{\mathrm{CHE}}$ of each household had two records: one before NCMS reimbursement and one after. We took it as a repeated-measures analysis. The dependent and independent variables are the prevalence status of CHE and reimbursement status of NCMS, respectively. We performed GEE with logit link to estimate the OR and 
95\% CI of the association between the $R_{\mathrm{CHE}}$ and NCMS reimbursement.

\section{Statistical analysis}

Categorical variables and expenditure measures were described by numbers (percentages) and means (SD), respectively. The annual household income in 2008 and 2013 was transformed by consumer price index (CPI) to the price level in 2003 with the following transformation formula: real price $=$ nominal price $\times($ CPI of base year $/$ CPI of object year). ${ }^{18}$ The annual household income was classified as quartiles. Three indicators above captured the catastrophe's incidence and intensity. We used stratification analysis to assess the 10-year trend of these indicators before and after NCMS reimbursement. The impact of NCMS in each year was reflected in the difference in CHE before and after reimbursement. The trend of difference from 2003 to 2013 reflected the overall change of the impact of NCMS. Data were disaggregated by three geographical regions (east, central and west) and four household income levels. The $R_{\mathrm{CHE}}$ of each household had two records in each year: one before NCMS reimbursement and one after. We took it as a repeated-measures analysis. GEE was used to estimate the OR and $95 \%$ CI of the association between the $R_{C H E}$ and NCMS reimbursement. Covariates including age, gender, education level, employment and marital status of the household head, household size, one or more members younger than 5 years, and one or more members older than 60 years were adjusted. All of the analyses were performed using SAS V.9.2. A two-sided $P<0.05$ was established as the level of statistical significance for all tests.

\section{RESULTS}

\section{Characteristics of households}

The characteristics of all households enrolled in the study in 2003, 2008 and 2013 are shown in table 1. The age of householders increased from 2003 to $2013 ; 49.38 \%$ of the householders were of age 60 or older in 2013. The proportion of households with one or more members younger than 5 years decreased from $17.78 \%$ in 2003 to $14.84 \%$ in 2013. The proportion of households with people of age 60 or older showed a $12.96 \%$ increase from 2003 to 2013. The proportion of householders with a junior high school or higher degree increased from $31.67 \%$ in 2003 to $40.17 \%$ in 2013 . The annual household income of each year was divided into quartiles, with each quartile cut-offs shifting upwards from 2003 to 2013.

\section{Incidence rates of CHE}

Table 2 shows the $R_{\mathrm{CHE}}$ among all the studied households. After NCMS reimbursement, the total $R_{\mathrm{CHE}}$ decreased rapidly, from $49.44 \%$ in 2003 to $34.88 \%$ in 2013. The change of the total $R_{\mathrm{CHE}}$ before and after reimbursement increased rapidly, from $9.45 \%$ in 2003 to $24.10 \%$ in 2013. A similar pattern was observed in different regions and different income levels. In addition, the poorest had the highest incidence, and the change in the west region was bigger than those in other regions.

\section{Severity of CHE}

The severity of CHE among all the studied households is shown in table 3. After NCMS reimbursement, the total $G_{\mathrm{CHE}}$ exhibited a decreased trend, from $12.57 \%$ in 2003 to $8.15 \%$ in 2013 . The change of the total $G_{\mathrm{CHE}}$ before and after reimbursement increased rapidly from $8.94 \%$ in 2003 to $33.50 \%$ in 2013 . Different regions and different income levels had similar patterns. In addition, the highest $G_{\mathrm{CHE}}$ was observed in the poorest areas. A similar trend could be observed in $M P G_{\mathrm{CHE}}$. The change of $M P G_{\mathrm{CHE}}$ was higher than that of $G_{\mathrm{CHE}}$ in each year.

\section{Influence of NCMS on the incidence rates of CHE}

Table 4 shows the influence of NCMS on $R_{C H E}$. In the aggregate, the $R_{C H E}$ before NCMS reimbursement was significantly higher than that after NCMS reimbursement, and the OR (95\% CI) was 1.46 (1.23 to 1.74), 1.70 (1.61 to 1.80 ) and 2.68 (2.54 to 2.83) in 2003, 2008 and 2013, respectively. The OR changed rapidly. There was a $16.44 \%$ increase in 2008 compared with 2003, and a $57.65 \%$ increase in 2013 compared with 2008. After adjustment of the covariates, the OR $(95 \% \mathrm{CI})$ was 1.50 (1.24 to 1.81 ), 1.79 (1.69 to 1.90$)$ and 2.94 (2.77 to 3.11 ) in 2003, 2008 and 2013, respectively. There was a 19.33\% increase in 2008 compared with 2003, and a 64.25\% increase in 2013 compared with 2008. A similar pattern was observed in different regions and at different income levels, but there were several exceptions in the central region and the lowest income groups in 2003, where the $R_{C H E}$ before NCMS reimbursement was not significantly higher than that after NCMS reimbursements. Among these covariates, the protection factors of the CHE were male gender of the householder, higher level of education of the householder and bigger household size. The risk factors of the CHE were having one or more members older than 60 and the older age of the householder (online supplementary materials).

\section{DISCUSSION}

According to the Chinese NHSS in 1998 and 2003, rural residents' health expenditures grew at an annual rate of $11.48 \%$, which was four times faster than their net income. ${ }^{18}$ High healthcare expenses in the absence of financial protection forced these rural households to fall into a difficult circumstance: "It's too difficult to see a doctor, and too expensive to seek health care!"18 In 2003, 96\% of rural households in China lacked medical insurance, and $38 \%$ of the sick did not seek medical attention. ${ }^{1318}$ To address this issue, NCMS was introduced to Chinese rural areas in 2003. With great efforts of the government, NCMS had experienced rapid growth in coverage. By 2011, 97.5\% of the rural population had been covered by NCMS in China. ${ }^{31819}$ This had fuelled 
Open Access

Table 1 Characteristics of all households enrolled in the study

\begin{tabular}{|c|c|c|c|c|c|c|}
\hline \multirow[b]{2}{*}{ Characteristics } & \multicolumn{2}{|c|}{$2003(n=180)$} & \multicolumn{2}{|c|}{$2008(n=2326)$} & \multicolumn{2}{|c|}{$2013(n=4469)$} \\
\hline & $n$ & $\%$ & $\mathbf{n}$ & $\%$ & $\mathbf{n}$ & $\%$ \\
\hline
\end{tabular}

Household characteristics

Number of household members

\begin{tabular}{|c|c|c|c|c|c|c|}
\hline$<5$ & 128 & 71.11 & 1916 & 82.37 & 3971 & 88.86 \\
\hline$\geq 5$ & 52 & 28.89 & 410 & 17.63 & 498 & 11.14 \\
\hline \multicolumn{7}{|c|}{ One or more members older than 60 years } \\
\hline Yes & 76 & 42.22 & 1059 & 45.53 & 2466 & 55.18 \\
\hline \multicolumn{7}{|c|}{ One or more members younger than 5 years } \\
\hline Yes & 32 & 17.78 & 378 & 16.25 & 663 & 14.84 \\
\hline \multicolumn{7}{|c|}{ Time spent travelling to the nearest medical centre } \\
\hline$\leq 15 \min$ & 145 & 80.56 & 1701 & 73.13 & 3532 & 79.03 \\
\hline$>15 \mathrm{~min}$ & 35 & 19.44 & 625 & 26.87 & 937 & 20.97 \\
\hline \multicolumn{7}{|c|}{ Number of observations in each region } \\
\hline \multicolumn{7}{|l|}{ Annual household income* } \\
\hline Q1 & 2643.33 & 1265.69 & 3956.52 & 1680.38 & 4785.49 & 2590.40 \\
\hline Q2 & 6914.23 & 1353.25 & 9062.74 & 1247.41 & 13003.64 & 2841.22 \\
\hline Q3 & 13505 & 2716.15 & 14699.42 & 2065.84 & 25958.15 & 5174.25 \\
\hline Q4 & 29194.35 & 10927.31 & 31665.48 & 20295.22 & 61082.23 & 44409.99 \\
\hline \multicolumn{7}{|l|}{ Householders' characteristics } \\
\hline \multicolumn{7}{|l|}{ Gender } \\
\hline Male & 131 & 72.78 & 1796 & 77.21 & 3373 & 75.48 \\
\hline Female & 49 & 27.22 & 530 & 22.79 & 1096 & 24.52 \\
\hline \multicolumn{7}{|l|}{ Age } \\
\hline Married & 155 & 86.11 & 1953 & 83.96 & 3735 & 83.58 \\
\hline Divorced & 0 & 0 & 29 & 1.25 & 612 & 13.69 \\
\hline Widow or others & 21 & 11.67 & 297 & 12.77 & 50 & 1.12 \\
\hline \multicolumn{7}{|l|}{ Education } \\
\hline Illiterate & 52 & 28.89 & 511 & 21.98 & 811 & 18.15 \\
\hline Elementary school & 71 & 39.44 & 917 & 39.44 & 1863 & 41.69 \\
\hline Junior high school & 48 & 26.67 & 722 & 31.05 & 1418 & 31.73 \\
\hline Senior high school or above & 9 & 5.00 & 175 & 7.53 & 377 & 8.44 \\
\hline \multicolumn{7}{|l|}{ Employment } \\
\hline Employed & 126 & 70.00 & 1817 & 78.12 & 3222 & 72.10 \\
\hline Retired & 12 & 6.67 & 60 & 2.58 & 157 & 3.51 \\
\hline Others & 42 & 23.33 & 449 & 19.30 & 1090 & 24.39 \\
\hline
\end{tabular}

*Annual household income of each year was divided into four levels according to the quartile, and the mean and SD of each level were calculated. 
Table 2 Incidence rates of catastrophic health expenses (CHE) among all the studied households (\%)

\begin{tabular}{|c|c|c|c|c|c|c|c|c|c|}
\hline \multirow[b]{2}{*}{$R_{\mathrm{CHE}}$} & \multicolumn{3}{|l|}{2003} & \multicolumn{3}{|l|}{2008} & \multicolumn{3}{|l|}{2013} \\
\hline & $\begin{array}{l}\text { Before } \\
\text { reimbursement }\end{array}$ & $\begin{array}{l}\text { After } \\
\text { reimbursement }\end{array}$ & Change & $\begin{array}{l}\text { Before } \\
\text { reimbursement }\end{array}$ & $\begin{array}{l}\text { After } \\
\text { reimbursement }\end{array}$ & Change & $\begin{array}{l}\text { Before } \\
\text { reimbursement }\end{array}$ & $\begin{array}{l}\text { After } \\
\text { reimbursement }\end{array}$ & Change \\
\hline Total & 58.89 & 49.44 & 9.45 & 54.90 & 41.75 & 13.15 & 58.98 & 34.88 & 24.10 \\
\hline East & 58.41 & 50.44 & 7.97 & 58.79 & 46.49 & 12.30 & 63.47 & 39.56 & 23.91 \\
\hline Centre & 85.71 & 85.71 & 0 & 49.54 & 38.47 & 11.07 & 57.13 & 35.51 & 21.62 \\
\hline West & 52.83 & 37.74 & 15.09 & 56.64 & 41.23 & 15.41 & 58.24 & 31.75 & 26.49 \\
\hline Q2 & 60.47 & 48.84 & 11.63 & 59.32 & 44.30 & 15.02 & 73.61 & 43.13 & 30.48 \\
\hline Q3 & 60.87 & 45.65 & 15.22 & 50.93 & 39.22 & 11.71 & 54.79 & 29.16 & 25.63 \\
\hline Q4 & 43.48 & 32.61 & 10.87 & 37.23 & 27.88 & 9.35 & 32.86 & 18.39 & 14.47 \\
\hline
\end{tabular}

a significantly increased consumption of health services due to previously latent unmet demand. From 2003 to 2008 , the inpatient hospital admission rate for rural residents almost doubled. ${ }^{1418}$ The $R_{C H E}$ of rural households with hospitalised members was much higher than other rural households. ${ }^{4}$ It was meaningful to evaluate the effectiveness of NCMS to provide financial protection specifically for these rural households with hospitalised members.

In our study, the $R_{C H E}$ of these households before NCMS reimbursement was $58.89 \%, 54.90 \%$ and $58.98 \%$ in 2003, 2008 and 2013, respectively (table 2). Approximately $60 \%$ of the households would fall into CHE and be susceptible to disease-induced poverty if they were not covered by NCMS in 3 years. After NCMS reimbursement, the $R_{C H E}$ decreased with different degrees, which were lowered to $49.44 \%, 41.75 \%$ and $34.88 \%$ in 2003, 2008 and 2013, respectively (table 2). The total $G_{\mathrm{CHE}}$ and $M P G_{\mathrm{CHE}}$ also decreased after NCMS reimbursement (table 3). The incidence and severity of $\mathrm{CHE}$ before NCMS reimbursement were higher than that after NCMS reimbursement in 3 years, which confirmed the effectiveness of NCMS to reduce CHE. Moreover, after adjustment of the covariates, $R_{C H E}$ was significantly associated with NCMS reimbursement $(P<0.05)$ (table 4$)$. To some extent, NCMS protected the rural households with hospitalised members from CHE. Inpatient reimbursement rates in rural areas had a remarkable achievement, increasing 7.5 times from $5.8 \%$ in 2003 to $43.7 \%$ in 2011. ${ }^{3}$ The financial protection in rural areas has been steadily improved. An apparent enhancement could be seen in this protective effect from 2003 to 2013, especially after the 2009 Health Care Reform. Having one or more members older than 60 in a household, female gender and older age of the householder, lower level of education of the householder and smaller household size increased the risk of incurring $\mathrm{CHE}$ in our study (online supplementary materials). This was consistent with the previous studies. ${ }^{40-23}$ NCMS should make preferential policies for these high-risk populations, such as providing special subsidies and an extra benefit package to them. As with targeted poverty alleviation, targeted policies should be designed to achieve targeted CHE alleviation among these households.

It was worth noting that the $R_{C H E}$ in rural households with hospitalised members in 3 years were all more than $34 \%$ after NCMS reimbursement, which meant that a number of households still faced CHE even though they were covered by NCMS (table 2). Many studies had shown that CHE was very likely to occur in households with poor economic conditions. ${ }^{24-27}$ The rural households with hospitalised members have heavy economic burdens and are likely to fall into such conditions. Thus, our study population tends to have higher proportion of $\mathrm{CHE}$ than previously reported in the whole rural households. Another reason for the high proportion of $\mathrm{CHE}$ in these households is the limited numbers of drugs and treatments included in the scope of NCMS. Under the fee-for-service payment system in China, doctors had strong incentives to prescribe expensive drugs and examinations not included by NCMS. ${ }^{4}$ NCMS needs to increase financial investment to expand its catalogue of essential medicines, especially for medicines that could increase the profits of medical institutions and pharmaceutical factories. An effective monitoring system is needed to restrain oversupply of expensive medical services and ensures that first-line generic medicines are available and preferentially prescribed.

We observed that all three indicators declined with the increase of household income in our study (table 2 and 3). Low-income households were more likely to incur CHE than other groups. One of the main reasons is their limited ability to pay for non-subsistence spending. These households are likely to fall into CHE, even as a result of low health expenditure. This phenomenon had also been experienced in many low-income/ middle-income countries in Asia. ${ }^{20} 27-29$ The inequalities of three indicators between different income groups still existed from 2003 to 2013 (table 2 and 3). Equity needs to be considered in the upgrade of NCMS. A higher share of resources should be allocated to areas with poor economic capacity, especially for low-income households, known as 'Dibaohu' in China. The current medical financial assistance scheme, which was a scheme designed to 


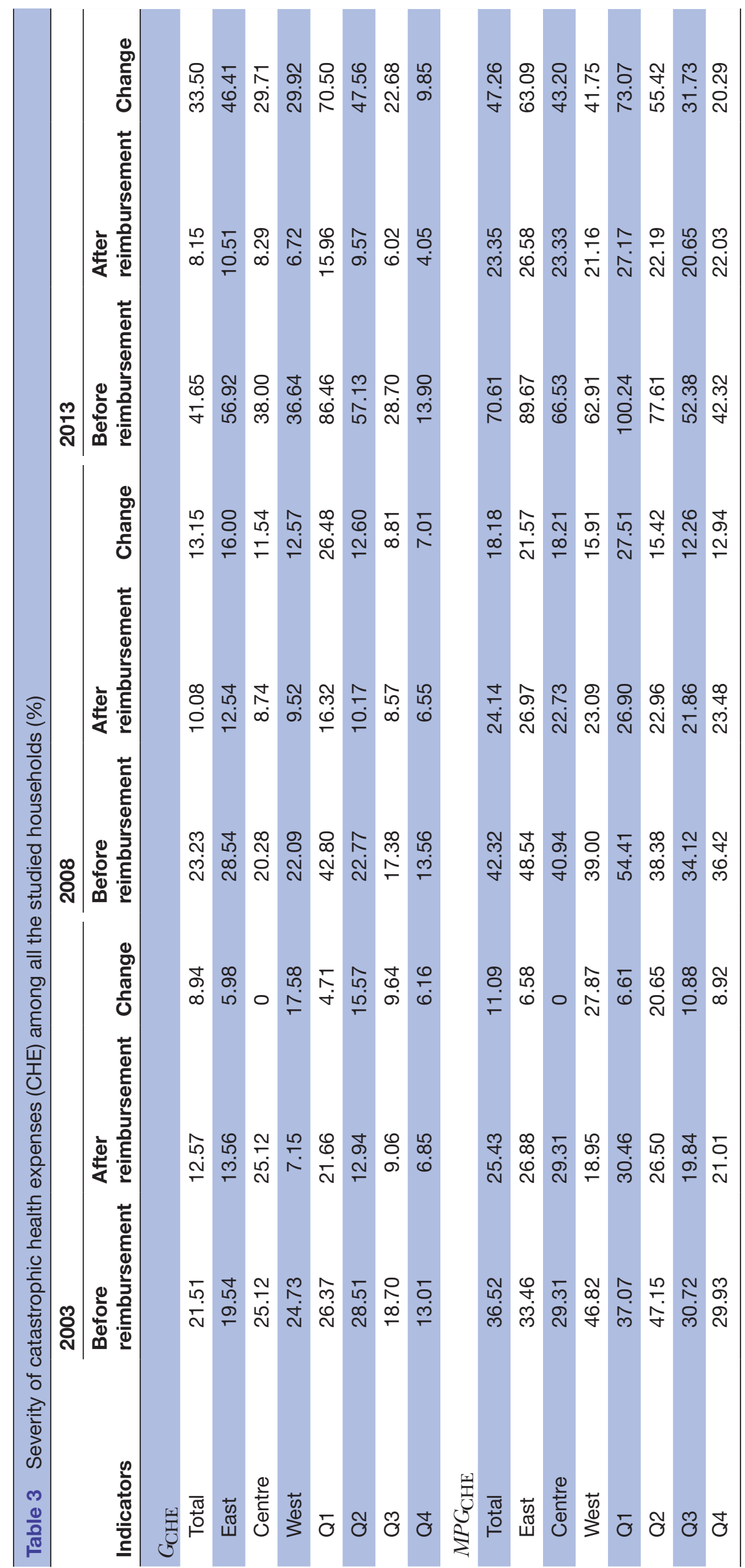


Table 4 Influence of the New Cooperative Medical Scheme on the incidence rates of catastrophic health expenses

\begin{tabular}{|c|c|c|c|c|c|c|}
\hline & & & Crude & & Adjusted & \\
\hline & Year & Change (\%) & OR $(95 \% \mathrm{Cl})$ & Increment (\%) & OR (95\% Cl) & Increment (\%) \\
\hline Total & & & & & & \\
\hline & 2003 & 9.45 & $1.46(1.23$ to 1.74$)$ & - & 1.50 (1.24 to 1.81$)$ & - \\
\hline & 2008 & 13.15 & $1.70(1.61$ to 1.80$)$ & 16.44 & 1.79 (1.69 to 1.90$)$ & 19.33 \\
\hline & 2013 & 24.10 & 2.68 (2.54 to 2.83 ) & 57.65 & 2.94 (2.77 to 3.11$)$ & 64.25 \\
\hline Area & & & & & & \\
\hline East & & & & & & \\
\hline & 2003 & 7.97 & 1.38 (1.13 to 1.69$)$ & - & $1.43(1.14$ to 1.80$)$ & - \\
\hline & 2008 & 12.30 & 1.64 (1.48 to 1.82$)$ & 18.84 & 1.77 (1.57 to 1.99$)$ & 23.78 \\
\hline & 2013 & 23.91 & 2.66 (2.37 to 2.97 ) & 62.20 & 3.08 (2.71 to 3.50 ) & 74.01 \\
\hline Cent & & & & & & \\
\hline & 2003 & 0 & $1.00(1.00$ to 1.00$)$ & - & 1.00 (1.00 to 1.00$)$ & - \\
\hline & 2008 & 11.07 & 1.57 (1.43 to 1.72$)$ & 57 & 1.64 (1.49 to 1.82$)$ & 64.00 \\
\hline & 2013 & 21.62 & 2.42 (2.23 to 2.63 ) & 54.14 & 2.63 (2.40 to 2.88 ) & 60.37 \\
\hline West & & & & & & \\
\hline & 2003 & 15.09 & 1.85 (1.24 to 2.75$)$ & - & 1.86 (1.23 to 2.82$)$ & - \\
\hline & 2008 & 15.41 & 1.86 (1.69 to 2.05 ) & 0.54 & 1.96 (1.77 to 2.16$)$ & 5.38 \\
\hline & 2013 & 26.49 & 3.00 (2.74 to 3.28 ) & 61.29 & 3.22 (2.93 to 3.55$)$ & 64.29 \\
\hline Income & & & & & & \\
\hline Q1 & & & & & & \\
\hline & 2003 & 0 & 1.00 (1.00 to 1.00$)$ & - & 1.00 (1.00 to 1.00$)$ & - \\
\hline & 2008 & 17.98 & 2.39 (2.03 to 2.81 ) & 139.00 & 2.56 (2.16 to 3.04$)$ & 156.00 \\
\hline & 2013 & 27.50 & 4.40 (3.70 to 5.24$)$ & 84.10 & 4.65 (3.89 to 5.55) & 81.64 \\
\hline Q2 & & & & & & \\
\hline & 2003 & 11.63 & 1.60 (1.08 to 2.37$)$ & - & 1.63 (1.08 to 2.45$)$ & - \\
\hline & 2008 & 15.02 & 1.83 (1.62 to 2.08 ) & 14.38 & 1.90 (1.67 to 2.16 ) & 16.56 \\
\hline & 2013 & 30.48 & 3.68 (3.19 to 4.25$)$ & 101.09 & 3.86 (3.32 to 4.49$)$ & 103.16 \\
\hline Q3 & & & & & & \\
\hline & 2003 & 15.22 & 1.85 (1.21 to 2.84$)$ & - & 1.89 (1.23 to 1.92$)$ & - \\
\hline & 2008 & 11.71 & 1.61 (1.44 to 1.80$)$ & -12.97 & 1.63 (1.46 to 1.83$)$ & -13.76 \\
\hline & 2013 & 25.63 & 2.94 (2.68 to 3.23 ) & 82.61 & 3.04 (2.76 to 3.35$)$ & 86.50 \\
\hline Q4 & & & & & & \\
\hline & 2003 & 10.87 & 1.59 (1.08 to 2.34$)$ & - & 1.62 (1.08 to 2.41$)$ & - \\
\hline & 2008 & 9.35 & 1.53 (1.39 to 1.69$)$ & -3.77 & 1.55 (1.41 to 1.72$)$ & -4.32 \\
\hline & 2013 & 14.47 & 2.17 (1.94 to 2.43$)$ & 41.83 & 2.21 (1.97 to 2.48 ) & 42.58 \\
\hline
\end{tabular}

provide support to the poor households for their CHE, should be further promoted to play a more efficient role in preventing CHE.

The changes of $R_{C H E}$ and OR before and after NCMS reimbursement in the west region were larger than the corresponding values in other regions in 3 years (table 2 and 4). A higher share of resources was allocated to the west region. The inpatient reimbursement rates in the east, central and west geographical regions in 2011 were $46.8 \%, 41.2 \%$ and $51.2 \%$, respectively. ${ }^{329}$ Almost all three indicators after NCMS reimbursement decreased rapidly from 2003 to 2008 but slowed down from 2008 to 2013 (table 2 and 3). This is due to the worst health situation in 2003 and the saturated health situation in $2008 .^{30} 31$

With the establishment of basic medical and health system and the improvement of residents' health consciousness, the demand for medical and health services has increased rapidly. Two-week prevalence rate of residents increased from $18.9 \%$ in 2008 to $24.1 \%$ in 2013 , the prevalence rate of chronic diseases increased from $24.1 \%$ in 2008 to $33.1 \%$ in 2013, and 
the rate of resident hospitalisation increased by $150 \%$ in the last 10 years. $^{32}$ Accordingly, medical expenditures have also increased rapidly. ${ }^{32} 33$ The financial protection of NCMS in rural areas faces great challenges. To further prevent CHE, NCMS should increase financing level to lower the deductibles and copayments, and set higher reimbursement rates and ceilings. A more effective cost control mechanism is also important.

This study has several strengths. First, to control the validity and reliability of statistical analysis, GEE, in view of its advantages, was used to estimate the OR and 95\% CI of the association between the catastrophe's incidence and NCMS reimbursement. Second, most studies focused on a specific local area or the shortterm effect of NCMS on CHE in China. We assessed the 10-year trend of the incidence and severity of CHE at the national level using data from the NHSS. Third, three indicators were used to capture the catastrophe's incidence and intensity, and data were disaggregated by three geographical regions and four household income levels. This study also has some limitations. First, NCMS was at the start stage in 2003 and the coverage was very low in rural China. Therefore, the sample size in 2003 was small with only 338 households. However, the impact of NCMS in 2003, 2008 and 2013 was reflected in the difference in CHE before and after reimbursement, and all the analyses were independently conducted in each year. In addition, we focused the overall trend of results from 2003 to 2013, and the sample size in 2003 had little influence on this trend. Second, we only focused on the rural households with hospitalised members covered by NCMS in this study. This limited the generalisability of the results considering that our results were specific to these households. Our findings should be interpreted cautiously. The inclusion of data from other countries should contribute to the ability to generalise the results of future studies.

\section{CONCLUSION}

The $R_{\mathrm{CHE}}, G_{\mathrm{CHE}}$ and $M P G_{\mathrm{CHE}}$ all decreased rapidly after NCMS reimbursement, and their changes increased rapidly from 2003 to 2013. After adjustment of the covariates, the $R_{\mathrm{CHE}}$ after NCMS reimbursement was significantly lower than that before NCMS reimbursements in each year. The NCMS partly protected the rural households with hospitalised members from CHE. The financial protection in rural areas had been steadily improved with the development of NCMS. However, inequalities between different groups still existed. The $R_{\mathrm{CHE}}$ in rural households with hospitalised members in 3 years were all more than $34 \%$ after reimbursement, which meant that many households still faced CHE even though they were covered by NCMS. To further prevent CHE, NCMS should increase financing level to provide a better benefit package and increase reimbursement rates, make preferential policies for the high-risk populations and low-income households, properly expand the catalogue of essential medicines, and establish effective supervision system. A high-quality healthcare in China will contribute to global health because of China's great population share in the world. Undoubtedly, the gain and loss during this reform will serve as reference for other countries, especially low-income/middle-income countries.

Acknowledgements The authors would like to thank all the participants in this study.

Contributors BX, ZW and MH drafted the manuscript. YC and RF performed data collection and statistical analyses. ML and QM made a substantial contribution to the interpretation of the data and study design. All authors read and approved the final manuscript.

Funding The research is funded by National Natural Science Foundation of China (81273183 to ML).

Competing interests None declared.

Patient consent Obtained.

Ethics approval The institutional review board of the Chinese National Bureau of Statistics provided review and ethics approval of the survey.

Provenance and peer review Not commissioned; externally peer reviewed.

Data sharing statement Original data are available on request. These were stored on password-protected computers at the Center for Health Statistics and Information of the Ministry of Health in Beijing, China.

Open Access This is an Open Access article distributed in accordance with the Creative Commons Attribution Non Commercial (CC BY-NC 4.0) license, which permits others to distribute, remix, adapt, build upon this work non-commercially, and license their derivative works on different terms, provided the original work is properly cited and the use is non-commercial. See: http://creativecommons.org/ licenses/by-nc/4.0/

(C) Article author(s) (or their employer(s) unless otherwise stated in the text of the article) 2018. All rights reserved. No commercial use is permitted unless otherwise expressly granted.

\section{REFERENCES}

1. Ministry of Health of the People's Republic of China. New Cooperative Medical Scheme in 2011. China: Ministry of Health of the People's Republic of China, 2012.

2. Xu K. Distribution of health payments and catastrophic expenditures methodology. Geneva: Department of Health System Financing, WHO, 2005.

3. Meng Q, Xu L, Zhang Y, et al. Trends in access to health services and financial protection in China between 2003 and 2011: a crosssectional study. Lancet 2012;379:805-14.

4. Li Y, Wu Q, Liu C, et al. Catastrophic health expenditure and rural household impoverishment in China: what role does the new cooperative health insurance scheme play? PLoS One 2014;9:e93253.

5. Sun YL, Xu Lz. The equity research of health service among urban and rural different professions residents in WeiHai. Chinese Health Service Management 2007;23:584-6.

6. Wu B. Dental service utilization among urban and rural older adults in China -- a brief communication. J Public Health Dent 2007;67:185-8.

7. Liang QJ, Zhang $X Y$, Shen $X$. The equity of health service utilization among urban and rural residents in China. Health Economics Research 2010;5:26-8.

8. Zhang ZG, Huang L. Research on the disparity and equalization between city and countryside of basic medical safeguard in China. Reformation \& Strategy 2011;27:176-9.

9. Hong LJ. Analysis of regional balance in maternal and children health services utilization and its change in China. AnHui, HeFei: AnHui Medical University, 2011.

10. Wang Q, Liu H, Lu ZX, et al. Role of the new rural cooperative medical system in alleviating catastrophic medical payments for hypertension, stroke and coronary heart disease in poor rural areas of China. BMC Public Health 2014;14:907. 
11. Liu Y, Rao K, Wu J, et al. China's health system performance. Lancet 2008;372:1914-23.

12. Center for Health Statistics and Information. Reports of nation health service survey summary, 2004

13. Center for Health Statistics and Information. Analysis report of national health services survey in China, 2008. Beijing: Center for Health Statistics and Information, Ministry of Health China, 2009.

14. Xu L, Wang Y, Collins CD, et al. Urban health insurance reform and coverage in China using data from National Health Services Surveys in 1998 and 2003. BMC Health Serv Res 2007;7:37.

15. Zeger SL, Liang KY. Longitudinal data analysis for discrete and continuous outcomes. Biometrics 1986;42:121-30.

16. Zeger SL, Liang KY, Albert PS. Models for longitudinal data: a generalized estimating equation approach. Biometrics 1988;44:1049-60.

17. Zhang H, Min J. A comparative study of GEE and MLM in a related data. Chinese Journal of Health Statistics 2012;29:214-6.

18. National Bureau of Statistics of China. National economic and social development statistics bulletin in 2011, 2012.

19. National Bureau of Statistics. China Statistical Yearbook. Beijing: China Statistical Press, 2009.

20. Xu K, Evans DB, Carrin G, et al. Protecting households from catastrophic health spending. Health Aff 2007;26:972-83.

21. Yardim MS, Cilingiroglu N, Yardim N. Catastrophic health expenditure and impoverishment in Turkey. Health Policy 2010;94:26-33.

22. Somkotra T, Lagrada LP. Which households are at risk of catastrophic health spending: experience in Thailand after universal coverage. Health Aff 2009;28:w467-78.
23. Li Y, Chi I, Zhang K, et al. Comparison of health services use by Chinese urban and rural older adults in Yunnan province. Geriatr Gerontol Int 2006;6:260-9.

24. Xu K, Evans DB, Kawabata K, et al. Household catastrophic health expenditure: a multicountry analysis. Lancet 2003;362:111-7.

25. Su TT, Kouyaté B, Flessa S. Catastrophic household expenditure for health care in a low-income society: a study from Nouna District, Burkina Faso. Bull World Health Organ 2006;84:21-7.

26. Waters HR, Anderson GF, Mays J. Measuring financial protection in health in the United States. Health Policy 2004;69:339-49.

27. Kawabata K, Xu K, Carrin G. Preventing impoverishment through protection against catastrophic health expenditure. Bull World Health Organ 2002;80:612.

28. Flores G, Krishnakumar J, O'Donnell O, et al. Coping with health-care costs: implications for the measurement of catastrophic expenditures and poverty. Health Econ 2008;17:1393-412.

29. Zhao $\mathrm{H}$. The significance of the new rural cooperative medical scheme for China. Theory Invest 2007;5:107-9.

30. Wagstaff A, van Doorslaer E. Catastrophe and impoverishment in paying for health care: with applications to Vietnam 1993-1998. Health Econ 2003;12:921-33.

31. Hu S, Tang S, Liu Y, et al. Reform of how health care is paid for in China: challenges and opportunities. Lancet 2008:372:1846-53.

32. Center for Health Statistics and Information. Analysis report of national health services survey in China, 2013. Beijing: Center for Health Statistics and Information, Ministry of Health China, 2016.

33. Zhou Z, Su Y, Gao J, et al. Assessing equity of healthcare utilization in rural China: results from nationally representative surveys from 1993 to 2008. Int J Equity Health 2013;12:34. 